Eleftherakis showed no improvement in performance tests when the concentrations of negative ions vjere increased. ${ }^{19}$ Other possible causes for the symptoms have been suggested, including the spectral quality of light from fluorescent lamps and photochemical smog catalysed by fluorescent lighting systems. ${ }^{2}$

The possibility that group suggestion may explain the increased prevalence of symptoms in the sealed building must be considered. Such suggestion could come from other workers or from the media in view of the current concern about these problems. This could give rise either to a "mass hysteria" effect or simply to heightened awareness in one particular group of people. Symptoms due to mass hysteria are usually vague, often neurological, and often associated with nausea, dizziness, and fainting. Hyperventilation may occur with these symptoms, which are mostly transient and resolve rapidly. ${ }^{20}$ None of these features were present in the workers that we saw.

The possibility of increased awareness in one particular group was minimised in our study by the management and unions from both buildings participating simultaneously throughout. The reason for the "medical survey" was not explained to the office workers. The prevalences of the various symptoms related to work have been found to differ consistently with different ventilating systems. ${ }^{6}$ Similarly, the prevalences of symptoms have been found to decrease after a change in ventilation and lighting systems. ${ }^{2}$ Both of these facts suggest that the cause is physical rather than psychological.

In conclusion, we believe that most of the respiratory, eye, and nasal symptoms in air conditioned buildings are related to the ventilation system. On current evidence lethargy and headache are probably related to factors other than the ventilation system. Factors that need investigating include the stability of the environment in sealed buildings, the effects of different types of work practice, and the removal of control of lighting and ventilation from the individual worker, as well as more extensive study of the quality of indoor atmosphere.

\section{References}

1 Turiel I, Hollowell CD, Miksch RR, Rudy JV, Young RA. The effects of reduced ventilation on indoor air quality in an office building. Atmospheric Environment

2 Sterling E, Sterling T. The impact of different ventilation levels and fluorescent lighting types on building illness: an experimental study. Can $\mathcal{F}$ Public Health

Sterling E, Sterling T, McIntyre D. New health hazards in sealed buildings. American Institute of Architects fournal 1983 April:64-7.

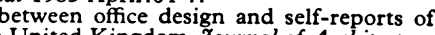
Kingdom. Fournal of Architecture and Planning Research 1984;3:163-74.

5 Hedge A. Ill-health amongst office workers: an examination of the relationship between office design and employee well-being. In: Grandjean E, ed. Ergonomics and health in modern offices. London: Taylor and Francis, 1984:46-51.

6 Finnegan MJ, Pickering CAC, Burge PS. Sick building syndrome: prevalence studies. Br Med fF 1984;289:1573-5.

7 Sterling TD, Sterling E, Dimich-Ward H. Building illness in the white-collar workplace. International fournal of Health Services 1983;13:277-87.

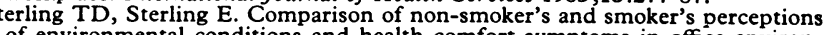
of environmental conditions and health comfort symptoms in office environments with and without smoking. In: Grandjean E, ed. Ergor

9 Chrenko FA, ed. Bedford's basic principles of ventilation and heating. 3rd ed. London: Lewis, 1974:26-7.

10 Gill FS, Ashton I. Monitoring for health hazards at work. London: Grant McIntyre Ltd, 1982:43-5.

11 National Institute for Occupational Safety and Health. Manual of analytical methods. 2nd ed. Vol 1. Ohio: National Institute for Occupational Safety and

12 McIntyre DA. Indoor climate. Barking, England: Applied Science Publishers Ltd,

13 Pickering CAC. Humidifier fever. Eur $\mathcal{F}$ Respir Dis 1982;63 (suppl 123):104-7S. 4 Burge PS, Finnegan MJ, Horsfield N, et al. Occupational asthma in a factory with a contaminated humidifier. Thorax $1985 ; 40: 248-54$.

15 Solomon WR. Fungus aerosols arising from cold-mist vaporizers. $f$ Allergy Clin Immunol $1974 ; 54: 222-8$.

16 Fanger PO. Thermal comfort. New York: McGraw Hill, 1972:19-64.

7 Breysse PA. The health cost of tight homes. $₹ A M A$ 1981;245:267-8.

lawkins LH. The influence of air ions, temperature and humidity on subjective wellbeing and comfort. Fournal of Environmental Psychology 1981;1:279-92. psye A, Eleftherakis E. Air ionization: an evaluation of its physiological and

20 Anychological effects. Annals of Occupational Hygiene 1982;25:409-19.

\title{
Nocturnal hypoglycaemia in patients receiving conventional treatment with insulin
}

\author{
S PRAMMING, B THORSTEINSSON, I BENDTSON, B RØNN, C BINDER
}

\begin{abstract}
The prevalence of nocturnal biochemical hypoglycaemia -that is, blood glucose concentrations below $3 \mathrm{mmol} / 1$ $(55 \mathrm{mg} / 100 \mathrm{ml}$ ) - was evaluated in a random sample of 58 insulin dependent diabetics receiving twice daily insulin. Seventeen patients had at least one blood glucose value below $3 \mathrm{mmol} / 1(55 \mathrm{mg} / 100 \mathrm{ml})$ and five a value below $2 \mathrm{mmol} / 1(36 \mathrm{mg} / 100 \mathrm{ml})$ during the night. Both bedtime (2300) and fasting morning (0700) blood glucose concentrations were significantly lower in the group
\end{abstract}

Steno Memorial Hospital, DK-2820 Gentofte, Denmark

$S$ PRAMMING, MD, research fellow

B THORSTEINSSON, MD, research fellow

B RØNN, MD

C BINDER, MD, chief physician

University Hospital, Hvidovre, Denmark

I BENDTSON

Correspondence to: Dr Pramming. with nocturnal hypoglycaemia compared with the group without $(p<0.00001)$. If the bedtime blood glucose concentration was below $6 \mathrm{mmol} / 1(108 \mathrm{mg} / 100 \mathrm{ml})$ the risk of nocturnal hypoglycaemia was $80 \%$ (95\% confidence limits 51-96\%). If the bedtime blood glucose concentration was above $6 \mathrm{mmol} / 1$ the likelihood of hypoglycaemia not occurring during the night was $88 \%$ (74-96\%).

The mean glycosylated haemoglobin $A_{1 c}\left(H_{b} A_{1 c}\right)$ concentration in the group with nocturnal biochemical hypoglycaemia $(8 \cdot 2$ (range $5 \cdot 0-12 \cdot 4) \%$ ) was significantly lower than that in the group without $(9 \cdot 4(7 \cdot 0-14 \cdot 2) \%)$ $(\mathbf{p}<0.02)$. The prevalence of nocturnal hypoglycaemia in the patients receiving twice daily insulin $(29 \%)$ was compared with that in 15 patients receiving thrice daily insulin $(47 \%)$ and was not found to be significantly different. The likelihood of this risk being greater with thrice daily insulin was, however, $88 \%$. No patient with nocturnal biochemical hypoglycaemia woke up during the night with symptomatic hypoglycaemia.

Nocturnal biochemical hypoglycaemia is common during twice daily treatment with insulin, and low values of $\mathrm{HbA}_{1 \mathrm{C}}$ might be associated with a higher risk of such hypoglycaemia. The blood glucose concentration at 
bedtime is a significant predictor of nocturnal biochemical hypoglycaemia, and $\mathbf{H b A}_{1 \mathrm{c}}$ values might be of help in identifying patients at risk.

\section{Introduction}

Diabetic patients treated with insulin must always rely on their ability to recognise the symptoms of impending hypoglycaemia to avoid serious hypoglycaemic episodes. This ability may be impaired during sleep. Little is known about the prevalence of nocturnal hypoglycaemia in patients treated with insulin, whether they are receiving conventional treatment or an intensified regimen. ${ }^{1-3}$ Patients were selected for these studies on the basis of stable $^{1}$ or labile ${ }^{2}$ metabolic control or were admitted for 24 hour profiles. ${ }^{4}$ The prevalence and symptomatology of nocturnal hypoglycaemia in unselected patients receiving conventional treatment with twice daily insulin injections have not been reported. The ability of the subjects to recognise and remember episodes of nocturnal hypoglycaemia has not been systematically examined, although this is relevant to patients and doctors when adjusting treatment with insulin.

This study attempted to estimate the prevalence of nocturnal biochemical hypoglycaemia (that is, blood glucose concentrations $<3 \mathrm{mmol} / 1(55 \mathrm{mg} / 100 \mathrm{ml})$ ) and symptomatic hypoglycaemia in patients receiving insulin injections two or three times daily. Furthermore, we aimed at finding the value of the blood glucose concentration at 2300 that predicted forthcoming nocturnal biochemical hypoglycaemia and to evaluate the subsequent morning fasting blood glucose concentration as an estimate of preceding nocturnal biochemical hypoglycaemia.

\section{Patients and methods}

The Steno Memorial Hospital sees most of the insulin dependent diabetic patients diagnosed in the county of Copenhagen and has files on more than 2500 such diabetics seen regularly. Most of these patients (about $80 \%$ ) receive a twice daily insulin regimen, with the morning injection of a mixture of soluble and intermediate acting insulin being given half an hour before breakfast. Roughly one third of the total insulin dose (mean $0.6 \mathrm{U} / \mathrm{kg}$ body weight for the clinic population) is then given before suppertime either as intermediate acting insulin alone or as intermediate acting insulin in a mixture with soluble insulin. Breakfast in Denmark is usually eaten at 0700, lunch at midday, and supper around 1800. The recommended diet is isocaloric and of high fibre content and contains $45 \%$ carbohydrate, $20 \%$ protein, and $35 \%$ fat. The diet is usually divided into three main meals and two or three snacks. The last snack is usually eaten around 2000 or 2100 .

Fifty eight patients receiving twice daily insulin and with a permanent address in the county of Copenhagen and 15 patients receiving three daily injections were chosen at random from the files of the outpatient clinic (table I). Patients receiving twice daily insulin took their insulin doses as described above. The group receiving thrice daily insulin took mixtures of soluble insulin just before supper and intermediate acting insulin before bedtime (2200-2300). All patients were admitted to the hospital at 2200 after a normal working day, having had their supper together with their suppertime insulin and evening snack at home. In hospital patients were allowed to drink and eat as they wished. They were asked to complete a questionnaire and score a list of symptoms, which included relevant hypoglycaemic symptoms, and were instructed to inform us immediately if they experienced subjective hypoglycaemia.

A cannula was inserted intravenously, and blood samples were drawn hourly throughout the night while patients were asleep. The samples were precipitated immediately with $3 \%$ trichloroacetic acid and stored until the next day, so that the blood glucose concentrations were not known to patients or observers during the study period. Blood glucose concentrations were measured in whole venous blood by a glucose oxidase technique (coefficient of variation $4 \%$ ), and glycosylated haemoglobin $\mathrm{A}_{1 \mathrm{c}}\left(\mathrm{HbA}_{1 \mathrm{c}}\right.$ ) (normal range $4 \cdot 1-6 \cdot 4 \%$ ) was measured as described elsewhere. ${ }^{5}$ The study was approved by the medical ethical committee of the county of Copenhagen, and all patients gave informed consent.

The unpaired $t$ test was used for statistical analysis. The predictive values were calculated according to the method of Vecchio. ${ }^{6}$ Values of $p<0.05$ were considered to be significant, and $95 \%$ confidence limits were obtained.

\section{Results}

Table II shows the numbers of patients in the two treatment groups in whom at least one sample yielded a blood glucose concentration below $3,2 \cdot 5$, and $2 \mathrm{mmol} / 1(55,45$, and $36 \mathrm{mg} / 100 \mathrm{ml})$ during the night.

PATIENTS RECEIVING TWICE DAILY INJECTIONS OF INSULIN

The figure shows the distribution of blood glucose concentrations below 3 and below $2 \mathrm{mmol} / 1$ ( 55 and $36 \mathrm{mg} / 100 \mathrm{ml}$ ) in the samples obtained hourly from the patients receiving twice daily insulin. The mean duration of hypoglycaemia was 3 (range 1-8) hours.

TABLE II-Number of patients in two treatment groups with low blood glucose concentrations during night

\begin{tabular}{llll}
\hline & \multicolumn{3}{c}{ Blood glucose concentrations $(\mathrm{mmol} / \mathrm{l})$} \\
\cline { 2 - 4 } Treatment group & $<3$ & $\leqslant 2.5$ & $<2$ \\
\hline Insulin twice daily $(\mathrm{n}=58):$ & $17(29)$ & $13(22)$ & $5(9)$ \\
$\quad$ No $(\%)$ of patients & $18-43$ & $13-35$ & $3-19$ \\
$95 \%$ confidence limits & $7(47)$ & $3(20)$ & $2(13)$ \\
Insulin thrice daily $(\mathrm{n}=15):$ & $21-73$ & $4-48$ & $2-41$ \\
No (\%) of patients: & & & \\
$95 \%$ confidence limits & & &
\end{tabular}

Conversion: SI to traditional units-Blood glucose: $1 \mathrm{mmol} / \mathrm{l} \approx 18 \mathrm{mg} / 100 \mathrm{ml}$

The maximal prevalence of blood glucose concentrations below 3 $\mathrm{mmol} / \mathrm{l}(55 \mathrm{mg} / 100 \mathrm{ml})$ was seen at 0400 . The bedtime blood glucose concentration (that is, the concentration at 2300 on the study night) was significantly lower in the 17 patients with nocturnal hypoglycaemia (mean 5.2 (range $1 \cdot 7-14 \cdot 1) \mathrm{mmol} / \mathrm{l}(97(31-254) \mathrm{mg} / 100 \mathrm{ml})$ ) than in the 41 patients without $(11 \cdot 0(4 \cdot 2-22 \cdot 3) \mathrm{mmol} / \mathrm{l}(198(76-401) \mathrm{mg} /$ $100 \mathrm{ml}))(\mathrm{p}<0.0001)$. The fasting blood glucose concentration at 0700 was also significantly lower in the group with nocturnal hypoglycaemia $(5 \cdot 3(1 \cdot 8-14 \cdot 8) \mathrm{mmol} / \mathrm{l}(95(32-267) \mathrm{mg} / 100 \mathrm{ml}))$ than in the group without $(11 \cdot 3(4 \cdot 7-22 \cdot 3) \mathrm{mmol} / \mathrm{l}(203(87-402) \mathrm{mg} / 100 \mathrm{ml})$ ) $(p<0 \cdot 0001)$. If the blood glucose concentration at bedtime was below $6 \mathrm{mmol} / 1(108 \mathrm{mg} / 100 \mathrm{ml})$ the risk of nocturnal hypoglycaemia (that is, at least one measurement of blood glucose concentration below $3 \mathrm{mmol} / 1(55 \mathrm{mg} / 100 \mathrm{ml}$ )) was $80 \%$ (confidence limits $51-96 \%$ ). Conversely, if the blood glucose concentration was above $6 \mathrm{mmol} / \mathrm{l}$ there was an $88 \%$ (confidence limits $74-96 \%$ ) likelihood of the patient not having a blood glucose concentration below $3 \mathrm{mmol} / \mathrm{l}(55 \mathrm{mg} / 100$ $\mathrm{ml}$ ) during the night. Furthermore, when the fasting morning blood glucose concentration was above $10 \mathrm{mmol} / 1(180 \mathrm{mg} / 100 \mathrm{ml})$ the possibility of the patient having had nocturnal hypoglycaemia was $4 \%$

TABLE I-Clinical data on insulin dependent diabetics selected for study. Values are means (and ranges)

\begin{tabular}{|c|c|c|c|c|c|c|c|}
\hline Treatment group & $\begin{array}{c}\text { Sex } \\
(\mathrm{F} / \mathrm{M})\end{array}$ & $\begin{array}{c}\text { Age } \\
\text { (years) }\end{array}$ & $\begin{array}{c}\begin{array}{c}\text { Duration of diabetes } \\
\text { (years) }\end{array} \\
\end{array}$ & $\begin{array}{l}\text { Total insulin dose } \\
\text { (IU/kg body weight) }\end{array}$ & $\begin{array}{c}\text { Evening insulin dose } \\
(\% \text { of total dose })\end{array}$ & $\begin{array}{c}\text { Bedtime insulin dose } \\
(\% \text { of total dose) }\end{array}$ & $\underset{(\%)}{\operatorname{HbA}_{10}}$ \\
\hline Twice daily insulin $(n=58)$ & $25 / 33$ & $\begin{array}{c}38 \\
(18-56)\end{array}$ & $\begin{array}{c}19 \\
(3-44)\end{array}$ & $\begin{array}{c}0.6 \\
(0.4-1.0)\end{array}$ & $\begin{array}{c}33 \\
(11-50)\end{array}$ & & $\begin{array}{c}9 \cdot 1 \\
(5 \cdot 0-14 \cdot 2)\end{array}$ \\
\hline Thrice daily insulin $(n=15)$ & $8 / 7$ & $\begin{array}{c}34 \\
(21-52)\end{array}$ & $\begin{array}{c}15 \\
(5-31)\end{array}$ & $\begin{array}{c}0.7 \\
(0 \cdot 5-1 \cdot 0)\end{array}$ & $(8-33)$ & $\begin{array}{c}21 \\
(8-36)\end{array}$ & $\begin{array}{c}8 \cdot 0 \\
(6 \cdot 4-10 \cdot 8)\end{array}$ \\
\hline Significance & NS & NS & NS & NS & & & $\mathbf{p}<0.05$ \\
\hline
\end{tabular}


(confidence limits $0-22 \%$ ), whereas if the blood glucose concentration was below $10 \mathrm{mmol} / \mathrm{l}$ the possibility of preceding hypoglycaemia was $53 \%$ (confidence limits $35-71 \%$ ).

The mean $\mathrm{HbA}_{1 \mathrm{c}}$ concentration was significantly lower in the group with hypoglycaemia $(8 \cdot 2(5 \cdot 0-12 \cdot 4) \%)$ than in those without hypoglycaemia $(9 \cdot 4(7 \cdot 0-14 \cdot 2) \%)(p<0.02)$.

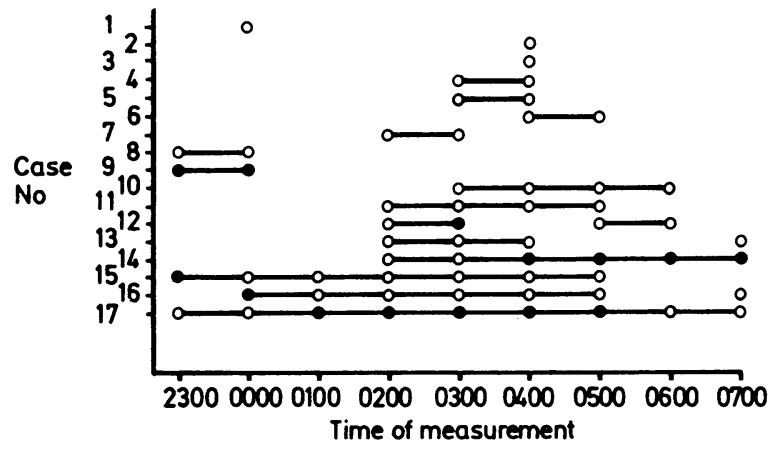

Night time distribution of blood glucose concentrations below $3 \mathrm{mmol} / 1(55 \mathrm{mg} / 100 \mathrm{ml})(\mathrm{O})$ and below $2 \mathrm{mmol} / 1(36 \mathrm{mg} / 100 \mathrm{ml})$ (O) in 17 diabetic patients receiving treatment with insulin twice daily and with nocturnal biochemical hypoglycaemia.

\section{PATIENTS RECEIVING THRICE DAILY INJECTIONS OF INSULIN}

Patients treated with insulin three times daily had a significantly lower mean $\mathrm{HbA}_{1 \mathrm{c}}$ concentration than those treated with insulin twice daily (table I). Seven of the 15 patients ( $47 \%$ ) had nocturnal hypoglycaemia. This prevalence, however, was not significantly different from the $29 \%$ found among patients treated with twice daily insulin. If the bedtime blood glucose concentration was below 6 $\mathrm{mmol} / \mathrm{l}(108 \mathrm{mg} / 100 \mathrm{ml})$ in the group receiving insulin thrice daily the risk of nocturnal hypoglycaemia was $100 \%$ (confidence limits 47$100 \%)$. Conversely, if the morning fasting blood glucose concentration was below $10 \mathrm{mmol} / \mathrm{l}(180 \mathrm{mg} / 100 \mathrm{ml}$ ) there was a $55 \%$ (confidence limits $23-83 \%$ ) possibility of the patient not having had nocturnal hypoglycaemia. The $\mathrm{HbA}_{1 \mathrm{c}}$ concentrations were not significantly different between patients with and without nocturnal hypoglycaemia $(7 \cdot 9(6 \cdot 8-10 \cdot 2) \%$ and $8 \cdot 1(6 \cdot 4-10 \cdot 1) \%$, respectively).

\section{SYMPTOMATIC HYPOGLYCAEMIA}

Forty two $(57 \%)$ of the 73 patients indicated in the questionnaire that they could detect periods of hypoglycaemia at night, $13(18 \%)$ said that they could not, and $18(25 \%)$ did not know. Thirty three $(45 \%)$ of the patients were certain that they had had previous episodes of nocturnal hypoglycaemia, whereas $15(21 \%)$ were certain that they had not and $25(34 \%)$ indicated that they did not know.

During the study night three patients woke up complaining of symptomatic hypoglycaemia. Their blood glucose concentrations later proved to be $12 \cdot 4,11 \cdot 3$, and $6 \cdot 2 \mathrm{mmol} / 1(223,203$, and $112 \mathrm{mg} / 100 \mathrm{ml}$ ), and none of these patients experienced biochemical hypoglycaemia during the study. None of the patients with biochemical hypoglycaemia woke up during the night, and only one was sure that he had been hypoglycaemic. On waking this patient could not move his right arm and leg. He was given glucose intravenously and the symptoms immediately resolved. He had experienced similar problems at home two or three times and reported that symptoms invariably vanished when he took glucose orally. Knowing that he would be unable to use the right arm, he always placed his glucose tablets to the left beside his bed. This patient was 22 years old and had had diabetes for seven years; he received an insulin dose of $0.98 \mathrm{U} / \mathrm{kg}$ body weight and usually did not have any trouble recognising the symptoms of hypoglycaemia during daytime.

\section{Discussion}

Overnight control of blood glucose concentration seems to be the weak point of conventional treatment with insulin. The prevalence of nocturnal hypoglycaemia has been reported as varying between $24 \%$ and $65 \%$ in different diabetic popula- tions. ${ }^{12} 4$ In our study almost one third of the patients chosen at random from a large number of insulin-dependent outpatients had at least one measurement of blood glucose concentration below $3 \mathrm{mmol} / \mathrm{l}(55 \mathrm{mg} / 100 \mathrm{ml})$ during the night.

Ideally, the patients should have been studied at home while sleeping in their usual surroundings. This would be possible, however, only if glucose sensors were used to monitor the blood glucose concentration continuously. As this cannot be done two alternatives exist: either to ask patients to take one or more blood samples at home or to admit patients overnight after they have had their usual food and insulin at home. The first approach has three major limitations. Firstly, the patients, if hypoglycaemic, may not be able to wake up at night and take blood samples properly. Secondly, more than one blood sample needs to be taken during the night. This study shows that if a single blood glucose sample was taken at either 0300 or 0400 only about two thirds of the episodes would be detected. Finally, obtaining several blood samples during the night at home will interrupt the sleep, which might therefore not be representative of a usual night's sleep. Similarly, admitting the patients to hospital may itself bias the results. We tried to minimise this effect by asking the patients to eat normally and take their usual insulin dose at home.

In clinical practice blood glucose concentrations measured at night are seldom used to evaluate the prevalence of nocturnal hypoglycaemia. Therefore, clinicians have no alternative but to ask about symptomatic episodes or measure morning blood glucose concentrations, or both. Our study shows that bedtime blood glucose concentrations can be of use, as the risk of nocturnal hypoglycaemia with a twice daily insulin regimen was $80 \%$ when the concentration at 2300 was below $6 \mathrm{mmol} / 1(108 \mathrm{mg} / 100$ $\mathrm{ml}$ ). It is almost a dogma that hypoglycaemia begets hyperglycaemia-commonly designated the Somogyi phenomenon. ${ }^{78}$ None of the patients with nocturnal hypoglycaemia in our study and a similar study ${ }^{9}$ showed any tendency towards this phenomenon. In fact, the mean morning blood glucose concentration in the group with hypoglycaemia was significantly lower than that in the group without hypoglycaemia. Moreover, a high fasting morning blood glucose concentration $(>10 \mathrm{mmol} / \mathrm{l}$ $(180 \mathrm{mg} / 100 \mathrm{ml})$ ) almost excluded preceding nocturnal hypoglycaemia. The $\mathrm{HbA}_{1 \mathrm{c}}$ concentration may also be a useful indicator of risk of nocturnal biochemical hypoglycaemia as the mean value in the patients with hypoglycaemia was significantly lower than that in the patients without.

It thus appears that many of the patients taking twice daily insulin and at risk of nocturnal hypoglycaemia can be found among patients normally considered to show good or excellent control-that is, patients with bedtime blood glucose concentrations below $6 \mathrm{mmol} / 1(108 \mathrm{mg} / 100 \mathrm{ml})$, fasting morning values below $10 \mathrm{mmol} / \mathrm{l}(180 \mathrm{mg} / 100 \mathrm{ml})$, and $\mathrm{HbA}_{1 \mathrm{c}}$ concentrations below $8 \%$.

Symptoms were of little clinical value as none of the patients with biochemical hypoglycaemia woke up during the night complaining about symptomatic hypoglycaemia, whereas only one of 17 patients with hypoglycaemia was certain on waking in the morning that he had been hypoglycaemic during the night.

In other studies it was found that during experimentally induced hypoglycaemia by means of intravenous infusion of insulin recumbent patients seldom experienced subjective hypoglycaemia before the blood glucose concentration became $2 \mathrm{mmoi} / 1 \mathrm{l}(36 \mathrm{mg} / 100 \mathrm{ml})$ or lower. ${ }^{10}$ In the present study even blood glucose concentrations lower than $2 \mathrm{mmol} / \mathrm{l}$ did not wake the patients. Introduction of a third insulin injection before bedtime has been suggested as a remedy for the "dawn phenomenon." "The theoretical benefit would be a more balanced delivery of insulin during the night and increased insulin concentrations in the morning, when the need is greatest. In patients taking three injections of insulin daily the mean fasting blood glucose concentration was about $2 \mathrm{mmol} / 1(36 \mathrm{mg} / 100 \mathrm{ml})$ lower than in the group taking twice daily insulin, and nocturnal hypoglycaemia was not significantly more prevalent. The risk of a 
type 2 error is, however, $88 \%$ with the present data from the two groups. It would require a much larger number of patients taking thrice daily insulin than 15 to show a possible significant difference. The important point is, however, that nocturnal hypoglycaemia is unlikely to be less prevalent with a thrice daily regimen. It remains to be shown whether any conventional regimen can reduce the prevalence of nocturnal biochemical hypoglycaemia and give normal fasting morning blood glucose concentrations at the same time. Continuous subcutaneous insulin infusion offers relatively constant and reproducible insulin profiles, ${ }^{12}$ but it has yet to be shown to reduce the prevalence of nocturnal hypoglycaemia.

Whether biochemical asymptomatic hypoglycaemia during the night is harmful cannot currently be answered satisfactorily. The changes seen in neuropsychological performance ${ }^{13} 14$ and on electroencephalography ${ }^{15}$ when the blood glucose concentration is acutely lowered to hypoglycaemic values seem reversible. Hypoglycaemia does not appear to be harmful provided it is of short duration, although this has never been studied properly. During the night, when alarm symptoms seem to be impaired, the possibility of long and severe hypoglycaemic periods exists. Such periods repeated over years of treatment with insulin could result in morphological and functional changes, primarily in the brain. When aiming for more physiological blood glucose control by means of intensified treatment with insulin it is thus important to evaluate not only the risk of daytime hypoglycaemia but also that of nocturnal hypoglycaemia.

In conclusion, asymptomatic biochemical hypoglycaemia at night is common during twice daily treatment with insulin and unlikely to be less common with thrice daily insulin regimens. Low values of $\mathrm{HbA}_{1 \mathrm{c}}$ might be associated with a higher risk of nocturnal biochemical hypoglycaemia. The bedtime blood glucose concentration seems to be a valuable predictor of nocturnal biochemical hypoglycaemia, and $\mathrm{HbA}_{1 \mathrm{c}}$ values might also be helpful in identifying patients at risk.

\section{References \\ 1 Winter RJ, Stone NJ, Wise JE, et al. Standard parameters of diabetic control: are they reliable? Diabetes Care 1979;2:336-4 \\ Gale EAM, Tattersall RB. Unrecognized nocturnal hypoglycaemia in insulin treated diabetics. Lancet 1979 ; i :1049-52. \\ Anonymous. Diabetic control at night [Editorial]. Lancet $1980 ; \mathrm{i}: 297-8$ \\ Dornan TL, Peckar CO, Mayon-White V, et al. Unsuspected hypoglycaemia, haemoglobin A, and diabetic control. $Q \mathcal{f}$ Med 1981;197:31-8. \\ Christiansen JS, Søgaard U, et al. Rapid changes in chromato- graphically determined haemoglobin $A_{1 c}$ induced by short term changes in \\ diagnostic test in unselected populations. $N$ Engl f Med 1966;274:1171-3. \\ Bloom ME, Mintz DH, Field JB. Insulin-induced posthypoglycaemia as a cause of "brittle" diabetes. Am $\mathcal{F}$ Med 1969;47:891-903. Somogyi M. Exacerbation of diabetes by excess insulin action. Am F Med 1959;
; \\ Gale EAM, Kurtz AB, Tattersall RB. In search of the Somogyi effect. Lancet $1980 ; \mathrm{i}: 279-82$ \\ 10 Marks V, Rose FC. Hypoglycaemia. 2nd ed. London: Blackwell, 1980. \\ Francis AJ, Home PD, Hanning I, et al. Intermediate acting insulin given at bed- time: effect on blood glucose concentrations before and after breakfast. $B r$ \\ 12 Lauritzen T, Pramming S, Deckert T, et al. Pharmacokinetics of continuous subcutaneous insulin infusion. Diabetologia 1983;24:326-9. \\ 13 Smith-Holmes C, Hayford JT, Gonzales JL, et al. A survey of cognitive function- ing at different glucose levels in diabetic persons. Diabetes Care 1983;6:180-4. Theilgaard A, Thorsteinsson B, Pinner EM, et al. Neuropsychological perfor- mance at different blood glucose concentrations in type 1 (insulin-dependent) diabetic patients. Diabetologia $1984 ; 27: 338$ \\ 15 Pramming S, Thorsteinsson B, Stigsby B, et al. EEG changes during hypoglycae- mia in type 1 (insulin-dependent) diabetic patients. Diabetologia 1984;27. \\ (Accepted 20 May 1985)}

\title{
Long term treatment of severe obesity: four year follow up of results of combined behavioural modification programme
}

\author{
H BJÖRVELL， S RÖSSNER
}

\begin{abstract}
A four year programme of treatment for severe obesity combining standard techniques such as behavioural modification, exercise, nutritional advice, and, in addition, readmission of patients who relapse has been developed. One hundred and seven subjects of both sexes were treated. Thirty nine had their jaws fixed from the start. After four years 104 out of 107 subjects were traced; $33(31 \%)$ had left the programme. The mean loss of weight in the remaining 74 subjects was $11.7 \mathrm{~kg}$ (range -20 to $55.5)$ : 14 had lost more than $20 \mathrm{~kg}, 35$ had lost $5-20 \mathrm{~kg}, 17$ had lost $0-5 \mathrm{~kg}$, and eight were above their weight before treatment. The rate of dropping out in this study was lower than that generally reported.

Our data suggest that combined behavioural modification used as a programme for reducing weight may result in a substantial loss of weight for several years even for severely obese subjects.
\end{abstract}

\footnotetext{
King Gustav V Research Institute, Karolinska Institute and Department of Internal Medicine, Karolinska Hospital, S-104 01 Stockholm, Sweden

H BJORVELL, RN, doctor of medical science

$S$ ROOSSNER, MD, associate professor

Correspondence to: Dr $\mathrm{H}$ Björvell.
}

\section{Introduction}

In the treatment of severe obesity long term follow up is mandatory. Obesity is usually a lifelong condition. Most programmes of treatment, however, last only for weeks or months, and the evaluation of the results rarely lasts for a year or longer. ${ }^{1-3}$

For subjects with incapacitating obesity numerous surgical methods have been developed. Although these have been successful in many cases, they do not cure overweight. Failures, complications, and death may occur even in late stages. ${ }^{4}$ Furthermore, they require long term follow up, and normal weight is certainly not effortlessly maintained as was once expected. ${ }^{5}$ Even in cases of severe obesity, therefore, non-surgical methods can play an important part provided that these methods initiate a noticeable loss of weight, maintain that loss of weight, identify and prevent relapses, and lead to a high degree of compliance.

The long term effects of various single techniques of reducing weight have generally been poor. Combinations of techniques, however, such as behavioural modification, exercise, and nutritional instruction seem to have more success, ${ }^{6}{ }^{7}$ but long term approaches of this kind are uncommon. One reason for this is that many overweight patients drop out of the programmes. In several studies about $50 \%$ of subjects dropped out during the first year of follow up. ${ }^{8-11}$

We report the results of a long term programme that we developed, which combined standard techniques such as behavioural modification, exercise, nutritional advice, fixing the 